\title{
XYLITOL FROM RICE HUSKS BY ACID HYDROLYSIS AND Candida YEAST FERMENTATION
}

\author{
Magale K. D. Rambo, Daiane B. Bevilaqua, Carla G. B. Brenner e Ayrton F. Martins* \\ Departamento de Química, Universidade Federal de Santa Maria, 97105-900 Santa Maria - RS, Brasil \\ Débora N. Mario e Sydney H. Alves \\ Departamento de Microbiologia, Universidade Federal de Santa Maria, 97105-900 Santa Maria - RS, Brasil \\ Carlos A. Mallmann \\ Departamento de Medicina Veterinária Preventiva, Universidade Federal de Santa Maria, 97105-900 Santa Maria - RS, Brasil
}

Recebido em 9/6/12; aceito em 10/12/12; publicado na web em 4/4/13

\begin{abstract}
An investigation was conducted into the production of xylose by acid hydrolysis of rice husks and its subsequent bioconversion to xylitol. The parameters were optimised using the response surface methodology. The fermentation stage took place with the aid of the yeast species Candida guilliermondii and Candida tropicalis. An evaluation of the influence of several biomass pre-treatments was also performed. The effects of the acid concentration and hydrolysate $\mathrm{pH}$ on xylitol global yield were also assessed, and the highest yield of xylitol was $64.0 \%(w / w)$. The main products, xylose and xylitol, were identified and quantified by means of liquid chromatography.
\end{abstract}

Keywords: xylitol; fermentation; rice husks.

\section{INTRODUCTION}

Currently, the world's energy consumption is mainly based on fossil fuels, which are associated with serious environmental problems. As a result, the demand for alternative renewable sources of energy has intensified to meet the rising demand for energy and raw materials. One of the few sources that has the potential to meet these challenges is biomass, since it is the only renewable material rich in carbon. ${ }^{1}$ Biomasses with a high content of cellulose and hemicellulose can constitute excellent feedstocks for biorefineries, since they can be converted into sugars, which are high value-added raw materials, including xylitol, - a derivative of xylose ${ }^{2-4}$ Although it is found in fruits and vegetables, xylitol is usually produced synthetically by the catalytic hydrogenation of xylose. This process involves a number of purification stages, which increases final cost. Thus, the chemical conversion of xylose into xylitol faces several difficulties. ${ }^{5}$ Despite these obstacles, xylitol has been widely used in the food and pharmaceutical industries. ${ }^{6}$ As a result of these mitigating factors, studies have been conducted worldwide with the aim of producing xylitol on an industrial scale and at a lower cost; these studies have investigated lignocellulosic residues such as sugar cane bagasse, rice and wheat straw, corncobs, sorghum, eucalyptus wood and others. ${ }^{1-12}$ To the best of our knowledge, only a few papers dealing with the conversion of rice husks ( $\mathrm{RH}$ ) to xylitol are available in the literature. Research studies conducted with the aim of exploiting the economic potential of RH generally focus on a limited range of properties (e.g. combustibility and insulation) or on RH ash (adsorption, ceramics). ${ }^{13}$ There are also a few studies concerned with the conversion of RH to value-added products, which have included the production of acetic acid, methanol and acetone,${ }^{13}$ xylose or ethanol, ${ }^{13,14}$ and nanosilicas. ${ }^{15}$

This study is both part of a postgraduate dissertation and a major project investigating the conversion of residual $\mathrm{RH}$ into value-added products. An attractive feature of the microbial conversion of xylose to xylitol is that it does not require toxic catalysts and is relatively easy to perform. Many microorganisms, including Pichia, Debaryomyces and

*e-mail: martins@quimica.ufsm.br
Candida have already been investigated..$^{7,16-18}$ Among these, Candida converts xylose to xylitol at a high yield; however, due to the formation of inhibitors, a high xylitol concentration in the fermentation broth is difficult to obtain.

$\mathrm{RH}$ are the most abundant agricultural crop residue in southern Brazil, and approximately $1 \mathrm{t}$ of residual $\mathrm{RH}$ remains for every $4 \mathrm{t}$ of rice produced. ${ }^{19}$ Moreover, $\mathrm{RH}$ contain approximately 25-35\% hemicellulose which can, without difficulty, be hydrolysed to xylose and then converted to xylitol. In this study, the bioconversion of xylose was conducted with the aid of available Candida tropicalis and Candida guilhiermondii species after acid hydrolysis of RH. Several parameters were evaluated in order to achieve the highest xylitol yield.

For the optimisation of the hydrolysis process and RH hydrolysate treatment, response surface methodology (RSM) was employed, where central composite design (CCD) determined the optimum level of each of the significant variables. ${ }^{20}$

Liquid chromatography tandem mass spectrometry detection by means of electrospray ionisation (LC-ESI-MS/MS) was used to identify and quantify xylitol in the RH hydrolysate samples.

\section{EXPERIMENTAL}

\section{Reagents}

All reagents and solvents were of analytical grade and used without any further purification. The yeasts were provided by a covenant state institution. The analytical standard for xylose (> 98\%) was acquired from Sigma Aldrich (São Paulo, Brazil). Formic acid (>99.95\%) and acetonitrile (99.98\%) were of chromatographic grade (Mallinckrodt, Phillipsburg, NJ, USA). Calcium chloride, ammonium sulphate, ammonium hydroxide and hydrogen peroxide were obtained from Synth (São Paulo, Brazil). Sulphuric acid, sodium hydroxide and active carbon were purchased from Merck (São Paulo, Brazil), and the $\mathrm{RH}$ and rice bran were purchased from a local provider.

Ultrapure water (Millipore, Bedford, MA, USA) was used for the preparation of the mobile phase (Direct-Q UV3 ${ }^{\circledR}$, resistivity $18.2 \mathrm{~m} \Omega \mathrm{cm}^{-1}$ ). 


\section{Preparation and treatment of rice husks}

$\mathrm{RH}$ were provided by a local rice handler. After a grinding process in a micro mill and the separation of particles (which had diameters ranging from 0.180 to $0.300 \mathrm{~mm}$ ) the $\mathrm{RH}$ samples were washed with distilled water and dried in a kiln at $105^{\circ} \mathrm{C}$ for $8 \mathrm{~h}$.

Table 1 shows some pre-treatment experiments that were conducted with solutions of different concentrations of ammonium hydroxi$\mathrm{de}^{21}$ and hydrogen peroxide ${ }^{22}$ and the different sonication times. Tests were also carried out with untreated RH samples. Before hydrolysis, all the pre-treated and untreated samples were washed with distilled water again and dried for $8-12 \mathrm{~h}$ at $105^{\circ} \mathrm{C}$.

Table 1. Pre-treatments of the rice husks for the acid hydrolysis

\begin{tabular}{|c|c|c|c|c|c|}
\hline Pre-treatments & $\begin{array}{c}\text { Soaking } \\
(\mathrm{mL})\end{array}$ & $\begin{array}{l}\text { Time } \\
\text { (h) }\end{array}$ & $\begin{array}{c}\text { Temperature } \\
\left({ }^{\circ} \mathrm{C}\right)\end{array}$ & Effect $^{\mathrm{a}}$ & Ref. \\
\hline \multicolumn{6}{|l|}{$\mathrm{NH}_{4} \mathrm{OH}, v / v$} \\
\hline $5 \%$ & 100 & 7 & 70 & ++ & 18 \\
\hline $10 \%$ & & & & +++ & \\
\hline $20 \%$ & & & & - & \\
\hline \multicolumn{6}{|l|}{$\mathrm{H}_{2} \mathrm{O}_{2}, v / v$} \\
\hline $1 \%$ & 100 & 24 & 25 & +++ & 19 \\
\hline $2 \%$ & & & & ++ & \\
\hline $3 \%$ & & & & - & \\
\hline Distilled water & 100 & 12 & 105 & + & no \\
\hline \multicolumn{6}{|l|}{ Sonication, min } \\
\hline 30 & - & 24 & 50 & + & 19 \\
\hline 45 & & & & ++ & \\
\hline 60 & & & & + & \\
\hline
\end{tabular}

a + satisfactory; ++ good; +++ best; - unsatisfactory.

Different concentrations of sulphuric acid $(0.8-7.0 \% \mathrm{~m} / \mathrm{v})$ were tested for hydrolysis. Inhibitor removal from the hydrolysate was evaluated by varying the contact time (30-60 $\mathrm{min})$ and the amount of added active carbon (1.5-4.5 $\left.\mathrm{g} \mathrm{L}^{-1}\right)$. The effect of the final $\mathrm{pH}$ of the hydrolysate ( $\mathrm{pH} 2.5-8.0)$ on the xylitol yield was also assessed.

\section{Acid hydrolysis and detoxification}

With the aim of determining the best available yeast for xylitol production, a $1.0 \%$ sulphuric acid solution was added to a $5 \mathrm{~L}$ round bottle at a 1:10 proportion of dry mass RH:acid solution (100 g RH:1 $\mathrm{L}$ acid solution), and then submitted to autoclaving for $30 \mathrm{~min}$ at temperatures $\left(106,110,120,130\right.$ and $\left.134^{\circ} \mathrm{C}\right)$ optimised by factorial design. From each test batch (in triplicate), $400.00 \pm 0.45 \mathrm{~mL}$ of hydrolysate were obtained, then centrifuged and filtered to remove cellulignin. The resulting fraction was concentrated $(3 \mathrm{x})$ in a rotatory evaporator at $70{ }^{\circ} \mathrm{C}$ in order to achieve a xylose concentration of 40 $60 \mathrm{~g} \mathrm{~L}^{-1}$ and then supplemented with $2.5 \%(\mathrm{w} / \mathrm{v})$ active carbon and shaken $(200 \mathrm{rpm})$ at $50{ }^{\circ} \mathrm{C}$ for $1 \mathrm{~h}$. Following this, the hydrolysate was vacuum filtered and the $\mathrm{pH}$ adjusted to 5.5 with the aid of micro-pearls of $\mathrm{NaOH}$. All experiments were conducted in triplicate under the optimised parameters.

\section{Microorganisms and preparation of inocula}

The available yeasts were Candida guilliermondii, maintained in malt extract agar at $4{ }^{\circ} \mathrm{C}$, and Candida tropicalis, provided by a covenant laboratory. The inoculum was prepared from $24 \mathrm{~h}$ subcultures of the Candida guilliermondii and Candida tropicalis yeasts, using concentrate solutions $\left(\mathrm{g} \mathrm{L}^{-1}\right)$ of xylose (20.00), $\left(\mathrm{NH}_{4}\right)_{2} \mathrm{SO}_{4}(3.00)$, $\mathrm{CaCl}_{2} .2 \mathrm{H}_{2} \mathrm{O}(0.10)$ and rice bran extract (20.00). All the solutions were prepared, separated and sterilised at $121^{\circ} \mathrm{C}$ for $20 \mathrm{~min}$, except for the xylose solution, which was autoclaved at $112{ }^{\circ} \mathrm{C}$ for $15 \mathrm{~min}$. The solutions were mixed to obtain the desired proportion of nutrients in the culture. The inoculated flasks were incubated in a shaker under $200 \mathrm{rpm}$ at $30{ }^{\circ} \mathrm{C}$ for $24 \mathrm{~h}$. Subsequently, the cells were centrifuged (20 min, $1100 \times \mathrm{g}$ ) and re-suspended in fermentation medium.

\section{Fermentation medium}

The fermentation medium was prepared with concentrated/ treated RH hemicellulosic hydrolysate containing $90 \mathrm{~g} \mathrm{~L}^{-1}$ xylose in addition to the nutrients used for preparation of the inoculum. The medium was inoculated with $3.0 \mathrm{~g} \mathrm{~L}^{-1}$ of the initial cellular broth. $\mathrm{pH}$ was adjusted to 4.5 with a $6 \mathrm{~mol} \mathrm{~L}^{-1} \mathrm{NaOH}$ solution. The experiments were conducted in $125 \mathrm{~mL}$ flasks containing $50 \mathrm{~mL}$ of fermentation medium, incubated at $30{ }^{\circ} \mathrm{C}$ and shaken at $200 \mathrm{rpm}$. Aliquots were taken during fermentation at intervals of $10 \mathrm{~h}$, monitoring the xylose consumption and xylitol production. The fermentation process was stopped at $106 \mathrm{~h}$; the fermentate was centrifuged at $100 \mathrm{rpm}$ for 20 min to separate the cells and to determine xylitol content.

\section{Liquid chromatography}

For the determination of xylitol, an Agilent Series 1100 liquid chromatograph equipped with a column oven, binary pump, autosampler and degasser was used. The operational conditions used were as follows: column XDB C18 (5 $\mu \mathrm{m}$; 4.6 x $150 \mathrm{~mm})$; mobile phase A (1\% v/v formic acid) and mobile phase B (acetonitrile 1\% v/v formic acid), using a gradient program starting with mobile phase $\mathrm{A}$ with a flow of $300 \mu \mathrm{L} \mathrm{min}^{-1}$ from 0 to $6 \mathrm{~min}$, following by mobile phase $\mathrm{B}$ at $1000 \mu \mathrm{L} \mathrm{m^{-1 }}$ from 6.01 to $7 \mathrm{~min}$, returning to the initial conditions until reaching $12 \mathrm{~min}$. The column oven temperature was kept at 30 ${ }^{\circ} \mathrm{C}$ and the injection volume was $5 \mu \mathrm{L}$.

\section{Mass spectrometry}

The compounds were quantified by means of an Applied Biosystems/MDS Sciex API 4000_Qtrap triple quadrupole mass spectrometer with Turbo Ion Spray ionisation. Positive ESI mode was used. The optimisation of the mass spectrometer was conducted by direct infusion of $10 \mu \mathrm{L} \mathrm{min}^{-1}$ of a $100 \mu \mathrm{g} \mathrm{L}^{-1}$ working solution of the analyte. Once the ionisation mode and the precursor ion had been selected, the automated quantitative optimisation feature was used to determine the product ions, as well as their corresponding declustering potential, collision energies, and exit potential. Quantification and confirmation transitions were monitored for the analyte.

The condition of the electrospray ionisation source was optimised by flow injection of a standard solution containing $100 \mu \mathrm{g} \mathrm{L}^{-1}$ of xylitol. The operating conditions were as follows: curtain gas 20 psi, spraying gas $40 \mathrm{psi}$, drying gas $50 \mathrm{psi}$, ionisation temperature $550{ }^{\circ} \mathrm{C}$, collision gas medium (low, medium and high) and ion spray voltage of $4000 \mathrm{~V}$. Multiple reaction monitoring (MRM) mode was employed for quantification.

\section{Validation of method}

The performance of the LC-ESI-MS/MS method was investigated by injecting analytical standards. However, a lack of a hydrolysate matrix free of the analyte precluded the performing of recovery studies. The accuracy of the retention times of the selected analyte was evaluated for qualitative purposes. Sensitivity (LOD and LOQ), linearity and precision were also studied. Sensitivity was estimated experimentally by taking the lowest concentration level able to reach a signal-to-noise $(\mathrm{S} / \mathrm{N})$ ratio of 3 for the LOD and a ratio of 10 for the LOQ. Linearity 
was evaluated by diluting the standard of the analyte into a series of 6 concentrations in the 5-400 $\mathrm{g} \mathrm{L}^{-1}$ range. The calibration curve showed a regression coefficient $\left(\mathrm{r}^{2}\right)$ higher than 0.999. The samples were diluted in methanol within the linear range for the determinations.

\section{Experimental design}

The experiments pertaining to xylitol production were conducted by evaluating the variables and values proposed by RSM, using a star design with $2^{2}+2 x^{2}+3=11$ experiments. This involved using the independent variables of hydrolysis temperature and fermentation time, and the dependent variable, global yield of xylitol.

The effect of these variables on the production of xylitol was investigated by RSM using CCD. The variance tables (ANOVA) were used to determine which factors (and their effects) were statistically significant.

\section{RESULTS}

\section{Production of xylitol with Candida yeasts}

The RSM graphs were drawn to illustrate the main interactive effects between the independent and dependent variables on the xylitol production process (Table 2).

Table 2. Factorial design of the xylitol production by C. tropicalis and $C$. guilliermondi

\begin{tabular}{|c|c|c|c|c|c|c|}
\hline Variables & \multicolumn{2}{|c|}{-1.41} & -1 & 0 & 1 & 1.41 \\
\hline (A) Time $(\mathrm{h})^{*}$ & \multicolumn{2}{|c|}{38} & 48 & 72 & 96 & 106 \\
\hline (B) Temperature $\left({ }^{\circ} \mathrm{C}\right) * *$ & \multicolumn{2}{|c|}{106} & 110 & 120 & 130 & 134 \\
\hline \multirow{2}{*}{ Experiments } & \multirow{2}{*}{ A } & \multirow{2}{*}{ B } & \multicolumn{4}{|c|}{ Yields $(\%)$} \\
\hline & & & \multicolumn{2}{|c|}{ C. tropicallis } & \multicolumn{2}{|c|}{ C. guilliermondil } \\
\hline 1 & -1 & -1 & & 7.30 & \multicolumn{2}{|r|}{30.00} \\
\hline 2 & +1 & -1 & & 7.00 & \multicolumn{2}{|r|}{32.00} \\
\hline 3 & -1 & +1 & & 1.12 & \multicolumn{2}{|r|}{10.00} \\
\hline 4 & +1 & +1 & & 1.27 & \multicolumn{2}{|r|}{12.00} \\
\hline 5 & -1.41 & 0 & & 5.60 & \multicolumn{2}{|r|}{12.00} \\
\hline 6 & 1.41 & 0 & & 5.70 & \multicolumn{2}{|r|}{16.00} \\
\hline 7 & 0 & -1.41 & & 7.70 & \multicolumn{2}{|r|}{40.00} \\
\hline 8 & 0 & 1.41 & & 1.30 & \multicolumn{2}{|r|}{8.00} \\
\hline 9 & 0 & 0 & & 6.60 & \multicolumn{2}{|r|}{13.00} \\
\hline 10 & 0 & 0 & & 6.00 & \multicolumn{2}{|r|}{11.00} \\
\hline 11 & 0 & 0 & & 6.50 & \multicolumn{2}{|r|}{12.00} \\
\hline
\end{tabular}

* fermentation time; **acid hydrolysis temperature.

Figure 1a outlines a typical RSM second-order model for xylitol production, showing the interaction between temperature and fermentation time. The response is spherical, increasing gradually when there is a lowering of the hydrolysis temperature and decreasing when there is a rise in temperature. This means that higher temperatures (120-135 ${ }^{\circ} \mathrm{C}$ ) are conducive to cellulose hydrolysis and the degradation of the hemicellulose fraction, thus confirming the low yields under more severe conditions. Under mild conditions $\left(106-110^{\circ} \mathrm{C}\right)$ hemicellulose provides better yields of xylose, and hence of xylitol. Figure $1 \mathrm{~b}$ shows that the reaction time hardly affects the process.

Therefore, xylitol production with Candida tropicalis achieved a maximum yield of only $7.7 \%$ at $106{ }^{\circ} \mathrm{C}$, yet with Candida guilliermondii, the yield was as high as $40.0 \%$. This supports the data from

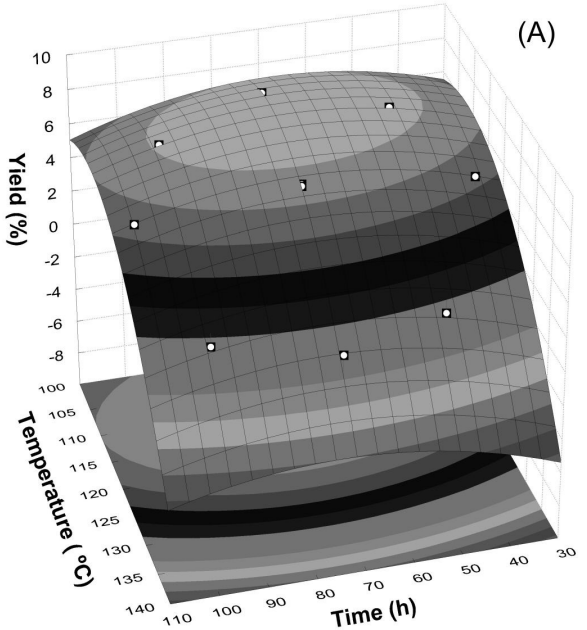

(B)

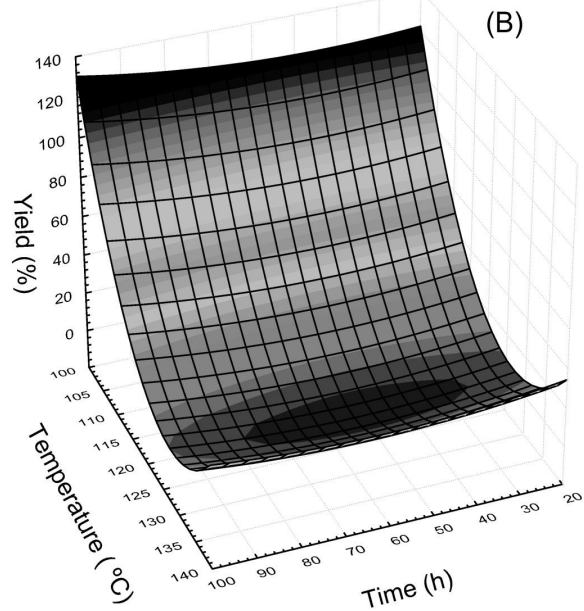

Figure 1. Quadratic model of the response surface for the xylitol production: (A) with Candida tropicallis and $(B)$ with Candida guilliermondii

the literature, since an increase in the hydrolysate-yeast contact time leads to higher xylitol yields, and peaks after $96 \mathrm{~h}$ of fermentation. This is also in accordance with the results for xylitol production from rice straw, where a maximum was achieved at $108 \mathrm{~h}$ of fermentation. ${ }^{23}$ If the differences between the raw materials are disregarded, the process followed in this study can be considered more efficient in terms of fermentation time.

According to the Pareto diagram (Figure 2a), variations in temperature have a significant effect both on the quadratic and linear models. The variable time for Candida tropicalis fermentation shows no significance with $95 \%$ confidence in both models. In the case of Candida guilliermondii, only the temperature exerts a significant influence, which is explained by the linear and quadratic equations, as shown in the Pareto diagram (Figure 2b). The quadratic model only explains the variable temperature for both designs.

The ANOVA showed a model that was satisfactorily adjusted to the experimental data, demonstrated by the determination coefficients $\mathrm{R}^{2}$ of 0.98 and 0.94 for the designs with Candida guilliermondii and Candida tropicalis, respectively.

\section{LC-ESI-MS/MS and validation}

The quantification and confirmation transitions were monitored to optimise the mass spectrometer. The quantification transition selected was that of the most abundant instrument response for the best sensitivity, while the confirmation transition selected was the 

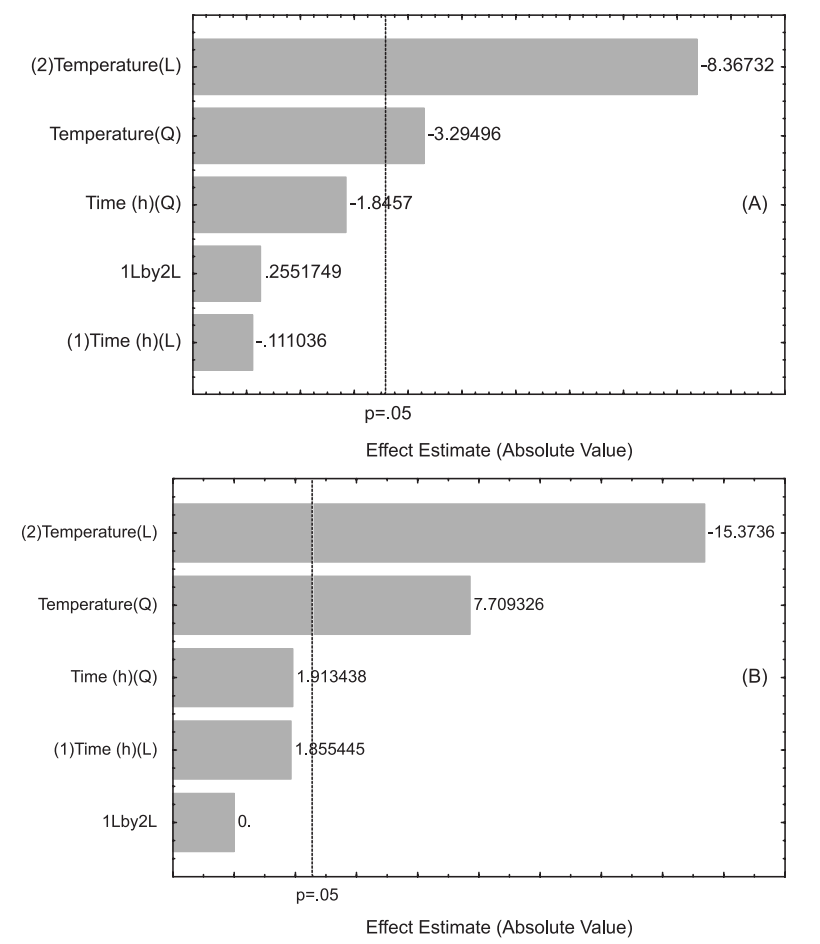

Figure 2. Pareto chart for the central compound diagram $2^{3}$ of the xylitol production: (A) with Candida tropicallis and $(B)$ with Candida guilliermondii. Q: quadratic model and L: lineal model

second-most abundant intensity. The $\mathrm{MS}^{2}$ mass spectrum identified quantification fragments $(\mathrm{m} / \mathrm{z}, 153.2)$ and a confirmation fragment $(\mathrm{m} / \mathrm{z}, 135.2)$. The best conditions for xylitol were obtained with a chromatographic run of $12 \mathrm{~min}$, where the analyte emerges at 5.12 min, as can be seen in the Supplementary Material (Figures $1 \mathrm{~S}$ and $2 \mathrm{~S}$, supplementary material).

The mean average of three injections of the analytical standard was taken by determining the LOD and LOQ of the method. There were no differences in the retention time of the analyte when the standard solution was injected, as well as the fermentate. The figures-of-merit resulting from method development are displayed in Table 3.

Table 3. Figures-of-merit for the determination of xylitol by LC-ESI-MS/MS

\begin{tabular}{lc}
\hline Figures-of-merit & \\
\hline Linear range $(\mu \mathrm{g} \mathrm{L}-1)$ & $5.0-400.0$ \\
Regression coefficient $\left(\mathrm{r}^{2}\right)$ & 0.9995 \\
Equation of straight line & $\mathrm{Y}=2.8 \mathrm{x}+718$ \\
$\mathrm{LOD}(\mu \mathrm{g} \mathrm{L}-1)$ & 1.5 \\
LOQ $(\mu \mathrm{g} \mathrm{L}-1)$ & 5.0 \\
Retention time $\left(\mathrm{min}^{-1}\right)$ & 5.12 \\
\hline
\end{tabular}

\section{Effects of pre-treatment}

Examination of Figure 3a shows that the best yield was obtained in the $96 \mathrm{~h}$ experiment applied to the hydrolysate of $1 \% \mathrm{v} / \mathrm{v}$ hydrogen hydroxide pre-treated RH. In contrast, the worst result was obtained in the $24 \mathrm{~h}$ experiment with the hydrolysate of pre-treated $\mathrm{RH}$ with $3 \% \mathrm{v} / \mathrm{v}$ hydrogen hydroxide. This means that when the hydrogen peroxide concentration increased, there was greater degradation of hemicellulose, which lowered the concentration of the resultant xylose in the hydrolysate.

For the alkaline solution, a decline in the xylitol yield was observed with an increase in the concentration of the ammonium hydroxide
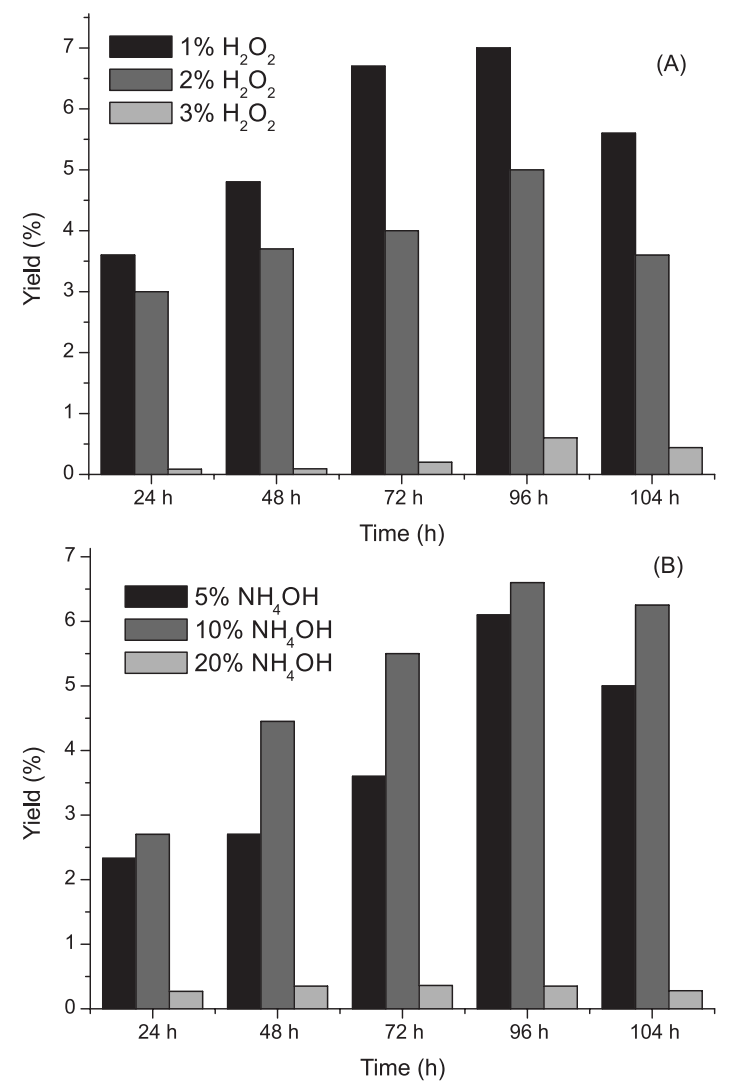

Figure 3. Xylitol yields by rice husks pre-treatment with (A) hydrogen peroxide solution and (B) ammonium hydroxide solution

solution, regardless of the fermentation time, which was possibly due to an increase in the degradation of lignin and polysaccharides (Figure $3 b) .{ }^{24}$ On the other hand, under moderate conditions (5 and $10 \% \mathrm{v} / \mathrm{v}$ ), the xylitol yield increased significantly, particularly with $96 \mathrm{~h}$ of fermentation, for both yeasts. The reason for this may be that, under such conditions, only the lignin bonds are broken, with no significant effect on hemicellulose.

Scanning electron microscopy (SEM) of the treated RH samples was undertaken to evaluate the physical effects on the pre-treated raw material and can be seen online in the Figure 3S, supplementary material.

\section{Effects of hydrolysate treatments}

Different concentrations of sulphuric acid, active carbon additions and inhibitor removal times were tested, together with different $\mathrm{pH}$ levels. The hydrolysate obtained under the best conditions was fermented with Candida tropicalis under the optimised conditions previously set up for this strain.

\section{Effects of acid concentration}

A higher xylitol yield was obtained with low sulphuric acid concentrations. High concentrations reduced the yield as a result of xylose degradation and the formation of potential inhibitors during the bioconversion to xylitol.

\section{Effects of active carbon treatment}

A factor of great importance in the bioproduction of xylitol with hemicellulosic hydrolysates is the presence of inhibitors of microbial metabolism, which interfere with the activity of some 
Table 4. Comparison of the fermentation yields under different rice husks pre-treatments

\begin{tabular}{lccccc}
\hline \multirow{2}{*}{ Rice husks pre-treatment } & \multirow{2}{*}{ Yeast } & \multicolumn{2}{c}{ Xylitol } & \multicolumn{2}{c}{ Fermentation $^{\mathrm{a}}$} \\
\cline { 3 - 6 } & & Final broth $\left(\mathrm{mg} \mathrm{L}^{-1}\right)$ & Yield $(\%)$ & $\mathrm{y}(\%)$ & $\mathrm{Y}_{\mathrm{P} / \mathrm{s}}\left(\mathrm{g} g^{-1}\right)$ \\
\hline Ammonium hydroxide solution $(10 \%, v / v)$ & Candida guilliermondii & 526.0 & 6.50 & 64.0 & 0.60 \\
Hydrogen peroxide $(1 \%, v / v)$ & Candida guilliermondii & 562.0 & 7.00 & 66.0 & 0.62 \\
Sonication & Candida guilliermondii & 346.0 & 4.30 & 62.0 & 51.0 \\
Distilled water & Candida guilliermondii & 202.0 & 2.52 & 7.70 & 0.59 \\
Untreated & Candida tropicalis & 13.1 & 0.16 & 0.09 \\
Untreated & Candida guilliermondii & 89.2 & 1.11 & 40.0 & 0.40 \\
\hline
\end{tabular}

${ }^{\mathrm{a}} \mathrm{y}=$ fermentation efficiency; $\mathrm{YP} / \mathrm{S}=$ fermentation yield; conditions (fermentation time $96 \mathrm{~h}$; temperature $30^{\circ} \mathrm{C}$; substrate rice husks hydrolysate).

enzymes and impair the efficiency of the bioconversion of sugar to other products. ${ }^{23}$ Inhibition lowers the reaction kinetics and limits the productivity and yield.

The best conditions were obtained with the addition of $2.5 \mathrm{~g}$ of active carbon at any point during contact with the hydrolysate. When active carbon was absent, the xylitol yields were very low, which proves the absolute need for a detoxification process.

The process of removing interfering substances carried out in this study proved to be efficient and simple; this process only required one stage and provided similar results to others reported in the literature. The use of low solubility calcium hydroxide increases the reaction time and reduces the amount of fermentable sugar. ${ }^{25}$

\section{Effect of hydrolysate $\mathrm{pH}$}

The $\mathrm{pH}$ effect of the hydrolysate on the xylitol yield is important owing to the fact that the toxic influence of some inhibitors can be increased; if this does not occur, the solubility of some of the nutrients might be reduced, and thus impede their assimilation. The threshold limits are generally $\mathrm{pH} 2.5-8.0 .^{26}$

In this study, the optimised $\mathrm{pH}$ conditions were in the 4.5-5.5 range. Under very acidic conditions, the yield was affected negatively $(<5.0 \%)$. In alkaline medium, a decrease in xylitol production was apparent, which can be explained by the low solubility of some fermentation nutrients under basic conditions.

\section{Effects of rice husk pre-treatment}

Table 4 summarises the main results of this study. The optimal fermentation time and temperature of $96 \mathrm{~h}$ and $30{ }^{\circ} \mathrm{C}$ were used for all experiments. Xylose consumption during fermentation was consistently higher than $70 \%$. The maximum yield of xylitol, given as $\mathrm{Y}_{\mathrm{P} / \mathrm{S}}=0.60 \mathrm{~g} \mathrm{~g} \mathrm{~g}^{-1}$, where $\mathrm{P}$ is the initial concentration of xylitol $\left(\mathrm{g} \mathrm{L}^{-1}\right)$ and $\mathrm{S}$ is the difference between initial and final xylitol concentrations $\left(\mathrm{g} \mathrm{L}^{-1}\right)$, was determined in an experiment using $\mathrm{RH}$ pre-treated with a $10 \%$ ammonium hydroxide solution for $6 \mathrm{~h}$; this provided a $23.0 \%$ greater yield compared with the experiment using only distilled water. Furthermore, when a comparison was made with the experiment using untreated $\mathrm{RH}$, the increase was $51.0 \%$. Theoretically, the xylitol production yield from xylose is $1.0 \mathrm{~g} \mathrm{~g}^{-1}$, assuming negligible microbial growth, but the highest reported yields from Candida spp. are around $0.85 \mathrm{~g} \mathrm{~g}^{-1} .^{27}$

With regard to the efficiency of the process, $\mathrm{RH}$ pre-treatment with ammonium hydroxide provided superior results (up to $\mathrm{Y}_{\mathrm{X} / \mathrm{S}}=$ $64.0 \%$ ), which corresponds to an increase of $40.0 \%$ compared to the experiment with untreated RH. If the theoretical global yield is taken into account, which goes beyond the fermentation stage, the advantages are evident.

It is evident that the yeast Candida tropicalis provided a yield of only $7.0 \%$, with a low theoretical efficiency $\left(0.085 \mathrm{~g} \mathrm{~g}^{-1}\right)$, while Candida guilliermondii showed a maximum yield of $40.0 \%$. When Candida guilliermondii was used, the calculated mass yield was $0.28 \%(\mathrm{~m} / \mathrm{m})$, which corresponds to the production of $2.80 \mathrm{~kg}$ xylitol per ton of residual RH.

The values for the xylitol yield and fermentative efficiency of this study are below the maximum values found in the literature for other kinds of biomass. Nevertheless, it should be stressed that only common chemical laboratory equipment was used, together with simple active carbon treatment and, more importantly, fermentation with a non-selected micro-organism.

Analytical determination of the final hydrolysate was conducted by means of LC-ESI-MS with the aim of assessing the concentration of xylitol in the hydrolysates. Sequential mass spectrometry confirmed the presence of xylitol in the hydrolysate aliquot samples based on the fragments that were generated. Quantification and confirmation were carried out at the same retention time and measured by injecting the analytical standard.

\section{CONCLUSION}

From the results of this study, it can be concluded that the bioconversion of RH to xylitol and other similar bioproducts, can lead to the mitigation of an environmental problem and represents a valuable business opportunity for industry in the state of Rio Grande do Sul, Brazil.

By optimising the operational parameters, $\mathrm{pH}$, reaction time, temperature, concentration and types of yeast, $64.0 \%$ yields were obtained for the bioconversion of $\mathrm{RH}$ to xylitol.

The RSM/CCD methodology employed allowed optimal adjustment of the experiments, where the effects of the variables on efficiency were observable. Unlike variations in fermentation time, differences in temperature exerted a considerable influence on the hydrolysis experiments.

The ESI-LC-MS/MS methodology developed was applied to the determination of xylitol and, as expected, proved to be suited to the purpose, not requiring clean-up or derivatization stages.

\section{SUPPLEMENTARY MATERIAL}

Available at http://quimicanova.sbq.org.br, in pdf file and free access.

\section{ACKNOWLEDGMENTS}

The authors would like to express their gratitude to the CNPQ (National Council for Technological and Scientific Development) for its financial support and scholarships. The authors have declared no conflicts of interest. 


\section{REFERENCES}

1. Rodrigues, J. A. R.; Quim. Nova 2011, 34, 1242.

2. Sene, L.; Arruda, P. V.; Oliveira, S. M. M.; Felipe, M. D. G. A.; New Biotechnol. 2009, 25, 226.

3. Franceschin, G.; Sudiro, M.; Ingram, T.; Smirnova, I.; Brunner, G.; Bertucco, A.; Chem. Eng. Res. Des. 2011, 89, 631.

4. Schuchardt, U.; Ribeiro, M. L.; Gonçalves, A. R.; Quim. Nova 2001, 24 , 247.

5. Cheng, K-K.; Zhang, J-A.; Ling, H-Z.; Ping, W-X.; Huang, W.; Ge, J-P.; Xu, J-M.; Biochem. Eng. J. 2009, 43, 203.

6. Ling, H.; Cheng, K.; Ge, J.; Ping, W.; New Biotechnol. 2010, 28, 673.

7. Prakash, G.; Varma, A. J.; Prabhune, A.; Shouche, Y.; Rao, M.; Bioresour. Technol. 2011, 102, 3304.

8. Canilha, L.; Silva, J. B. A.; Solenzal, A. I. N.; Process Biochem. 2004, 39, 1909.

9. Mussatto, S. I.; Roberto, I. C.; Biotecnologia cienc. desenvolv. 2002, 28, 34

10. Tamanini, C.; Hauly, M. C. O.; Semina ciênc. agrar. 2004, 25, 315.

11. Huang, C. F.; Jiang, Y. F.; Guo, G. L.; Hwang, W. S.; Bioresour Technol. 2011, 102, 3322

12. Canilha, L.; Carvalho, W.; Felipe, M. G. A.; Silva, J. B. A.; J. Microbiol. 2008, 39, 333.

13. Reyes, J.; Peralta-Zamora, P.; Durán, N.; Quim. Nova 1998, 21, 140.
14. Ahmed, Z.; Banu, H.; Akhter, F.; Izumori, K. A.; Int. J. Biol. Sci. 2001, 11,1001 .

15. Ma, Y.; Zhao, X.; Zhang, H.; Wang, Z.; Ind. Crop. Prod. 2011, 33, 403.

16. Mussatto, S. I.; Roberto, I. C.; Braz. Arch. Biol. Technol. 2005, 48, 497.

17. Misra, S.; Gupta, P.; Raghuwanshi, S.; Dutt, K.; Saxena, R. K.; Purif. Technol. 2011, 78, 266.

18. Cortez, D. V.; Roberto, I. C.; Bioresour. Technol. 2010, 101, 1858.

19. Rambo, M. K. D.; Cardoso, A. L.; Bevilaqua, D. B.; Rizzetti, T. M.; Ramos, L. A.; Korndörfer, G. H.; Martins, A. F.; J. Agron. 2011, 10, 99.

20. Jaiswal, N.; Prakash, O.; Talat, M.; Hasan, S. H.; Pandey, R. K.; Asian J. Biochem. 2011, 6, 357.

21. Hendriks, A. T. W. M.; Zeeman, G.; Bioresour. Technol. 2009, 100, 10.

22. Yu, J.; Zhang, J.; He, J.; Liu, Z.; Yu, Z.; Bioresour. Technol. 2009, 100, 903.

23. Mussatto, S. I.; Roberto, I. C.; Biotechnol. Lett. 2001, 23, 1681.

24. Ko, J. K.; Bak, J. S.; Jung, M. W.; Lee, H. J.; Choi, I-G.; Kim, T. H.; Kim, K. H.; Bioresour. Technol. 2009, 100, 4374.

25. Gurgel, P. V.; Furlan, S. A.; Martinez, S. E. R.; Mancilha, I. M.; Braz. J. Chem. Eng. 1998, 15, 309.

26. Silva, S. S.; Felipe, M. G. A.; Mancilha, I. M.; Appl. Biochem. Biotechnol. 1997, 70, 331.

27. Granström, T. B.; Izumori, K.; Leisola, M. A.; Appl. Microbiol. Biotechnol. 2007, 74, 273. 


\section{XYLITOL FROM RICE HUSKS BY ACID HYDROLYSIS AND Candida YEAST FERMENTATION}

Magale K. D. Rambo, Daiane B. Bevilaqua, Carla G. B. Brenner e Ayrton F. Martins*

Departamento de Química, Universidade Federal de Santa Maria, 97105-900 Santa Maria - RS, Brasil

Débora N. Mario e Sydney H. Alves

Departamento de Microbiologia, Universidade Federal de Santa Maria, 97105-900 Santa Maria - RS, Brasil

Carlos A. Mallmann

Departamento de Medicina Veterinária Preventiva, Universidade Federal de Santa Maria, 97105-900 Santa Maria - RS, Brasil

Figure $1 \mathrm{~S}$ and $2 \mathrm{~S}$ shows the $\mathrm{MS}^{2}$ mass spectrum and the chromatograms of a standard solution of xylitol $\left(200 \mu \mathrm{g} \mathrm{L}^{-1}\right)$ and of the fermentation hydrolysate, respectively.

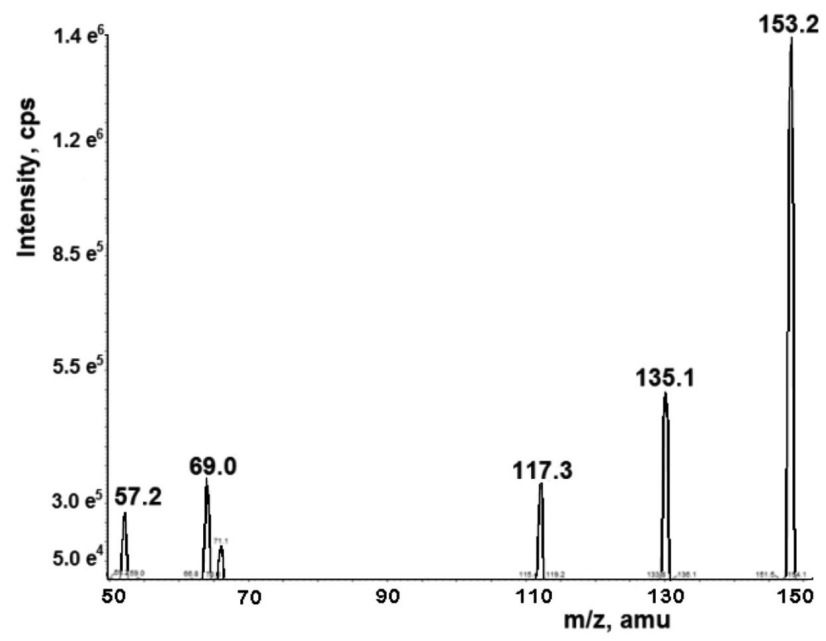

Figure 1S. MS2 Scan of direct infusion of a standard solution of xylitol

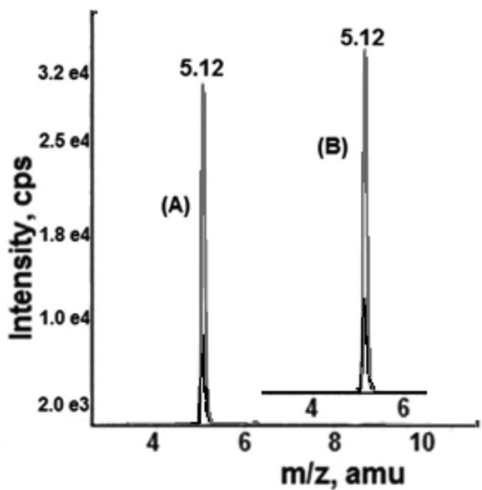

Figure 2S. Extracted ion chromatogram (XIC): (A) xylitol standard solution, (B) hydrolysate sample
Figure $3 \mathrm{~S}(\mathrm{~A})$ corresponds to the untreated $\mathrm{RH}$ and a well preserved epidermis with cellular structures covered with silica can be seen. Figure $3 \mathrm{~S}(\mathrm{~B})$ corresponds the RH soaked with distilled water, where no significant changes can be seen. Figure $3 \mathrm{~S}(\mathrm{C})$ allows the well organized epidermis to be identified as well as the fissures resulting from the peroxide treatment. When using $10 \% v / v$ ammonium hydroxide (Figure $3 \mathrm{~S}(\mathrm{D}))$ it is noticeable that the pre-treatment induced remarkable physical changes: the treated $\mathrm{RH}$ has a rough texture and some of the external structures are partially absent, which leads to an increase in surface area. When Figure $3 \mathrm{~S}(\mathrm{E})$ is examined, it can be observed that the epidermis is slightly affected by the ultrasound treatment.
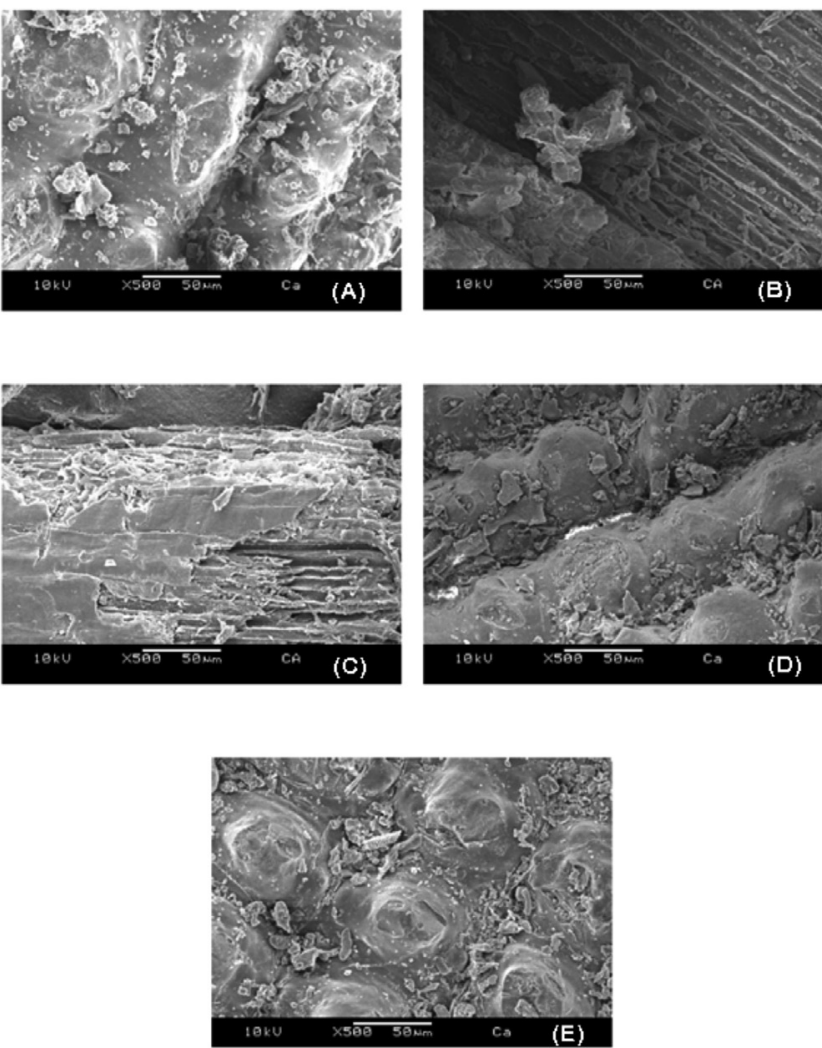

Figure 3S. Scanning electronic microscopy of rice husks submitted to different pre-treatments: (A) untreated rice husk, $(B)$ soaked in distilled water, $(C)$ soaked in $1 \% \mathrm{H}_{2} \mathrm{O}_{2},(D)$ soaked in $10 \% \mathrm{NH}_{4} \mathrm{OH}$ and $(E)$ sonicated 